adopted. There are preliminary data ${ }^{1,2}$ to suggest that coronectomy all but eliminates the risk of IDN injury but as yet the evidence is tenuous and definitive studies are required to confirm the suggestion.

A survey was undertaken to establish the current pattern of care in this regard in the UK, Australia and New Zealand with 320 individuals completing a questionnaire: consultants (45\%), associate specialists, specialty trainees, specialty dentist and primary care specialist practitioners (55\%) who removed an average of 609 MTM teeth each year. Of these, $76 \%$ felt coronectomy had a role in MTM surgery with 66\% willing to provide the procedure. However, most respondents did not believe coronectomy was an automatic choice for cases 'at risk' of IDN injury with it being offered only $40 \%$ of the time. Each individual carried out an average of ten coronectomies/year. CBCT was regarded by $89 \%$ as having a role (56\% had access to CBCT). Respondents estimated an average of 26 CBCTs were prescribed/ year for 'at risk' MTMs.

This indicates that CBCT and coronectomy are used selectively in current practice, that their role continues to divide opinion and that more evidence is required to clarify their optimal use. Clearly though, the routine use of CBCT or coronectomy is not the standard of care for the management of MTM deemed 'at risk' of IDN injury at the present time.

The authors would like to thank the societies and all the members of BAOMS, BAOS, ABAOMS and ANZAOMS for taking the time to kindly complete this survey.

V. Patel, M. McGurk

1. Renton T, Hankins M, Sproate C, McGurk M. A randomised controlled clinical trial to compare the incidence of injury to the inferior alveolar nerve as a result of coronectomy and removal of mandibular third molars. Br J Oral Maxillofac Surg 2005; 43: 7-12.

2. Leung $Y Y$, Cheung L K. Safety of coronectomy versus excision of wisdom teeth: a randomized controlled trial. Oral Surg Oral Med Oral Pathol Oral Radiol Endod 2009; 108: 821-827.

DOI: 10.1038/sj.bdj.2014.1063

\section{SPECIAL CARE DENTISTRY}

\section{Beard protection}

Sir, in these days of 'doom and gloom' in dentistry, I wanted to share with you something that really made me smile and appreciate what wonderful caring dental nurses can do to really enhance the patient experience. Working in Barts Health Community Dental Service, in the inner London area of Tower Hamlets, we see a lot of patients who often have very long beards. One of my patients is an elderly, very medically compromised, wheelchair-bound gentleman who needed

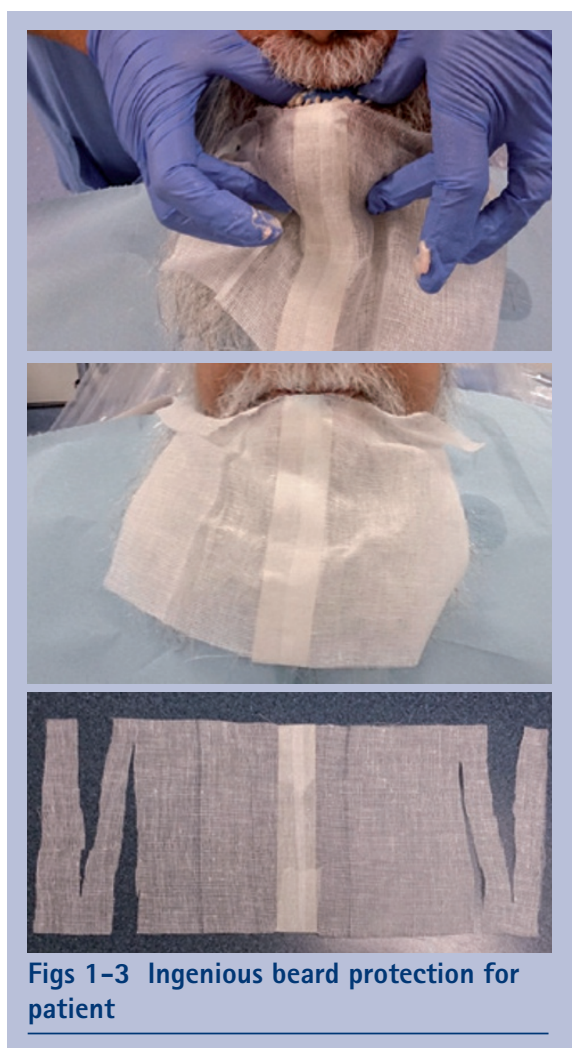

some new dentures as the hospital had lost his. When I entered the surgery the nurse had already helped him transfer to the dental chair and the patient was facing me. This is what I saw (Figs 1-3).

Was it a new type of religious covering, which I was unaware of? No - it's a novel beard protector! And it worked.

It was made from two gauze dental napkins and micropore. Value for money at 1.3 pence per square and with a very happy carer who said last time it took her ages to get the impression material out of the beard. We were all grateful to the wonderful dental nurse, Abdul Hye.

D. Simons

DOI: 10.1038/sj.bdj.2014.1064

\section{DENTAL PATIENTS}

\section{Delivering PCC}

Sir, we would like to congratulate Scambler and Asimakopoulou on the recent article $A$ model of patient-centred care (PCC) ${ }^{1}$ which highlights the importance and relevance of PCC within dentistry. Formulation of a model of PCC is an important step in the process of developing a tool that can be reliably used to assess patient experience, and this is particularly pertinent in view of the direction of travel of the proposed dental contract reforms.

We are currently conducting health services research on PCC from a patient's perspective, predominately focusing on the decision-making process, and we would agree that shared decision-making (SDM) is a fundamental aspect of PCC, but that other aspects need to be considered. Provision of information is repeatedly highlighted as a key component and our work has identified the importance of avoiding a one-directional view of this, with the clinician as the provider and the patient the recipient. It is important to acknowledge the role which the patient plays in 'providing' information such as symptoms, history, concerns, attitudes, values and beliefs in order for a clinician to make a diagnosis and formulate a treatment plan which can be used to support SDM.

For this, the clinician must have the skills to communicate, the time to listen and a desire to deliver PCC. The prevailing healthcare system has a profound influence on the ability to deliver PCC and the challenges in achieving this under the present UDAcentred contract need to be recognised.

The current Dental Quality Outcomes Framework (DQOF) ${ }^{2}$ predominately uses patient satisfaction indicators as a marker of 'patient experience'. This would seem entirely inappropriate as it is widely recognised that patient satisfaction is a poor and unreliable indicator of quality. ${ }^{3,4}$ The NHS Patient Experience Framework ${ }^{5}$ is closely aligned to the Picker Principles of PCC and it is important that any future iteration of the DQOF attempts to measure aspects of PCC rather than simply choosing to measure what is easy, over what is relevant.

Future work needs to inform the development of a reliable tool to measure PCC within general dental practice as it cannot be assumed to have been achieved simply by measuring the final outcome, without consideration to the process. Any tool designed to measure PCC needs to be able to assess the delivery of the 'foundational components', ${ }^{1}$ and this means it must involve more than just an assessment of shared decision making or patient satisfaction as an endpoint.

I. Mills, J. Frost, D. R. Moles, E. Kay,

by email

1. Scambler S, Asimakopoulou K. A model of patientcentred care - turning good care into patientcentred care. Br Dent J 2014; 217: 225-228.

2. Department of Health. Dental Quality and Outcomes Framework. London: The Stationery Office, 2011.

3. Schoenfelder T. Patient satisfaction: a valid indicator for the quality of primary care? Primary Health Care 2012; 2.4. Available at: http://omicsgroup.org/ journals/patient-satisfaction-a-valid-indicator-forthe-quality-of-primary-care-2167-1079.1000e106. pdf (accessed November 2014).

4. Cornwell J. What matters to patients? Developing the evidence base for measuring and improving patient experience. Coventry: NHS Institute, 2011.

5. Department of Health. NHS Patient Experience Framework. London: HMSO, 2012. Available at: http://www.dh.gov.uk/health/2012/02/patientexperience-framework/ (accessed November 2014).

DOI: 10.1038/sj.bdj.2014.1065 